\title{
THE IMPACT OF THE COMPANY'S IMAGE ON THE VALUE OF THE CUSTOMER BY ADOPTING THE SOCIAL RESPONSIBILITY APPROACH APPLIED RESEARCH IN SOME IRAQI MOBILE PHONE COMPANIES
}

\author{
Mohamed Ibrahim Jawad, Prof. Dr. SaadounHamoud Al-Rabawi \\ University of Baghdad / College of Management and Economics
}

DOI: $10.37648 /$ ijrssh.v10i01.010

Received:30 ${ }^{\text {th }}$ September, 2019; Accepted:30th October, 2019; Published: $20^{\text {th }}$ November, 2019

\begin{abstract}
This research aims to keep abreast of the scientific developments of its main variables (image of the company, social responsibility and customer value), in addition to conducting a practical analysis to find out what the relationship between those variables and evaluate the results of the analysis according to the hypothesis of impact. The experts distributed the questionnaire, and many statistical methods were used. Based on the research and occupation of importance by the mobile phone companies, and based on that formulated a set of conclusions that recommend the adoption of social responsibility as a way to improve customer value by building the image of the company and improve in the minds of customers.
\end{abstract}

Keywords: corporate image, customer value, social responsibility.

\section{INTRODUCTION}

This research came to form clear and comprehensive perceptions about the impact of the image of the company in building the value of the customer by adopting the approach of social responsibility, which is an intermediate tool in achieving this impact, in an attempt to apply to the Iraqi environment, and from this stand was built the basis of the research, and through the research problem of The research aims to maximize the value of the customer by building the image of the company and studying its impact on value with the help of social responsibility. The applied approach is derived from objectivity in order to derive hypotheses from the theoretical side in order to be able to test statistical and cognitive means and ensure their objectivity through a method of analytical survey of (250) customers of two Iraqi mobile phone companies (Cork Telecom Company and Asiacell Company) to make sure The impact of the company's image on the value of the customer by using statistical means among themselves by social responsibility.

In general, companies should understand that they should take care of the attitude of customers in general towards their products and activities because they affect the image of the company at the time of purchase (Kotler \& Armstrong, 2012), as the image of the 
company must convey all the meanings, lessons and benefits of the product to the customer and requires This is the process of developing and building the image of the company in a strong and distinctive and creative and actual work or hard where the image of the company can not be in the mind of customers overnight using a few ads must be supported by the image with all the company and do in order to reach the ideal image of the company in front of customers (Kotler \& Armstrong., 2012)

Companies need to adopt a specific approach in order to build customer value. Companies focus on financial benefits for the economic benefit of the customer, and through the structural benefits of close operational engagement with customers, there are social benefits based on relationships and social networking, supportive and personal interaction between companies And customers. (Drummond \& Ensor, 2001: 231-232) therefore, this research seeks to know the correlation and relationship between these variables and after reviewing most of the previous studies focused on the image of the company and the value of the customer and social responsibility, but there were no studies that combine these variables With some, as well as not to clarify the image of the company as a key variable.

\section{THEORETICAL FRAMEWORK}

\subsection{Concept of company image}

The image of the company through the study (Kandampully) is an important factor in the evaluation of any organization because of the strength that lies in the perception of customers when hearing the name of the company, as he stressed that the company's image consists of two main elements: Alnaser et al, 2017) The first element is a functional element such as concrete characteristics that can be easily measured and evaluated.

The second element is the emotional component of the feelings, attitudes and beliefs generated by the customer towards the organization and are the results of the accumulated experiences of the customer with the organization.

Keller defined the concept of corporate image as a subjective knowledge or attitude such as the name of the company, the reputation of the organization and the level of quality of the organization system, all of which in turn help to build the image of the company. For the accumulated feelings, ideas, attitudes and experiences with the organizations and stored in the memory of the customer, which can be turned into a positive or negative Gantt and is retrieved to reconfigure the image when you hear the name of the organization can be said from this, the image of the company is the result of the communication process in which the organizations established Specific message form the intentions of the strategic vision and goals and identity that reflects the basic values that cherish them for conformity with the vision. (Abd-El-Salam et al, 2013: 17).

Studies, magazines and periodicals have proved that the information used in the perception of the company image is related to different dimensions with organizations according to each organization and their business, dealings and trends such as: corporate identity, organizational culture, company behavior, communication policy, customer value, company image, mental image, brand image Organizations need to make efforts to manage the image of the company in order to secure themselves in a competitive business environment and maintain the trust of customers. Today, companies have to reach their goals and needs to clarify their success. A clearer form for all stakeholders, where studies after scientific discussions and various studies found that corporate identity leads to the image of the company and then the image of the company leads to the reputation of the company. (Tawfik, 2013)

\subsection{The Concept of Customer Value}

The concept of customer value from the point of view ((Kumar \&Reinartz) as he pointed out that the concept of customer value is critical to the management of customer relations and the value of the customer is an important decision means, and then to evaluate the effectiveness of marketing and companies can measure their marketing efforts and make them ideal by introducing The concept of customer value is at the heart of the decision-making process (Kumar \&Reinartz, 2010)

In the modern era, the business has focused on the value of the customer by giving or satisfying the needs and desires of the customers of modern and sophisticated 
products and services which they consider to be in line with what is expected or what is in the mind of the customer, which achieves value for the customer. Appropriately, since value is all that is valued by the customer, since value is created from time to time and from stage to stage, and this change is due to the needs and desires of the customer, the physical condition of the customer, the way of thinking, lifestyle and expectations.

It is also possible to clarify the value of the customer is essentially a concept that includes many heterogeneous factors and that the choice of the customer during the purchase process is made by many factors that include factors that include social, emotional, cognitive, financial belongings and the overall benefits of the service or product. To obtain something in order to obtain the benefits that the customer derives from companies, where the value of the customer can be linked to customer satisfaction where the value of the customer affect the satisfaction of customers. (Aslam, el at, 2018).

Finally, the value of the customer can be determined by studying and reviewing studies, periodicals and books. There have been many difficulties for many authors involved in determining value in an attempt to promote diverse definitions as suggested by Woodruff. The use of the terms and conditions that facilitate or prohibit the achievement of the customer's objectives or intent in the case of use, "although the multiple functions and criteria in this definition reflects the complexity in the concept that this definition is more relevant to the customer, on the other hand, the value of the customer $\mathrm{e}$ The difference between the values derived by the customer from the possession and use of the commodity and the cost of getting the item, on the other hand, it has to understand that the total customer value is the total value of the item and the value of the service and the value of the employee and the value of the picture to the Gantt costs of cash and temporary whole energy is assigned a total customer. (Yamamoto, 2002 565,).

\subsection{Corporate Social Responsibility}

CSR is about how organizations integrate their value and behavior with expectations from different stakeholders such as suppliers, employees, consumers and society as a whole (Maruf, 2013). CSR is meant to reduce the negative social, environmental and economic impacts it faces on the surrounding environment. CSR seeks to work in a way that contributes to sustainable development. There are many motivations to participate in CSR initiatives. Other stakeholders believe that social responsibility increases operational efficiency and reduces costs. In some countries, governments are working to reduce taxes as much as the work of organizations towards social responsibility. With CSR because it is the right foundation to do regardless of the economic impact (Ganescu, 2012), CSR is increasingly demanded by consumers when the importance of a sustainable approach While corporate social responsibility has influenced the policies and attitudes of organizations around the world, they are rarely linked to strategic marketing in order to influence CSR can be used as a resource and a way to gain a competitive advantage when organizations market their products in an ethical manner (Bhaduri, Selarka, 2016), (Carroll, 1979), as CSR issues are addressed by the organization. Product quality Since CSR is the decisive factor for organizations to work ethically with regard to the economic, social, cultural, political and technological environment, attention should be given to developing CSR strategies and grouping them as business practices, while CSR activities are categorized as inherent in products and product related activities. Commodityrelated organizations are particularly important for value-building (Asamoah, 2012), and studies continue to find that CSR is inherent Through products as well as attitudes and behaviors towards stakeholders by adding value to customers, many researchers have pointed out in their CSR study that they should be more selective through CSR reports that emphasize behaviors in the production process. And services towards customer orientation. (Agarwal g2013).

\section{RESEARCH TOOLS}

The hypotheses for this research were conducted by using multiple stepwise linear regression models according to the so-called structural equation modeling (SPSS24 and AMOS24), which is to study the direct effect of the company image variable as an independent variable in the customer value variable as an approved variable and the indirect effect of a variable. The image of the company in the value of the customer variable through the influence of the variable of social 
responsibility as an intermediate variable. 173$1192,1986)$, which is consistent with the mechanism used in the hierarchy of building the hypotheses of this research, as interpreted in succession:

a- Test the statistical significance of the relationship between the dimensions of the image of the company and the dimensions of social responsibility.

b- test the statistical significance requirement in the relationship between the dimensions of the variable image of the company and the value of the customer as an approved variable and expressed by the second main hypothesis of the research.

c- Test the statistical significance in the relationship between the dimensions of social responsibility and the value of the customer after the inclusion of the model for this test of the dimensions of the company's image variable as a control variable (control) has an expected effect in the interpretation of the relationship, thus the hypothesis of the effect of the intermediate variable in the adopted variable (response) in the presence of the independent variable. (Interpretative) and expressed by the third main hypothesis of the research

\section{TEST RESEARCH HYPOTHESES}

The first main hypothesis: emerged from this hypothesis seven sub-hypotheses resulting from the study of the relationship between the dimensions of the variable image of the company as an independent variable, and dimensions of the variable of social responsibility as a dependent variable and the following is the test results, respectively.

The first sub-hypothesis: The results of the hypothesis test shown in Table (1) showed the significance of the four-dimensional effect of both the mental image of the company with the strongest effect in terms of the beta plant $(23423, P=0.000=\beta)$ and after the brand image (.154, $\mathrm{P}=0.002$ (and after the product / service image with effect $(, 232, \mathrm{P}=0.002)$ and after the product $/$ service quality image $(007, P=0.002) \beta$ Among the dimensions of the independent variable represented by the company image in the economic dimension is the first dimension of The social responsibility variable as an intermediate variable, and the test results did not demonstrate a significant effect of the dimension of the corporate identity image $(55=0.05, \mathrm{P}>0.05)$ in the economic dimension, while the power of interpretation was The model according to the coefficient of interpretation or determination $(\mathrm{R} 2=.66)$, which was also statistically significant $(P=0.000)$, this reflects the variance $(66 \%)$, which is explained by the company's image through its dimensions, mental image of the company, brand image, product image / The quality of the product / service, in particular, from the variation of the economic dimension being studied in the context of achieving economic benefit objectives aimed at improving the image of the company in front of its customers, while the rest of the ratio of the coefficient of variance (34\%), is subject to other influence factors that fall outside the scope of the current research Not being of his current interests. 
Table 1: Test results of the first sub-hypothesis of the first main hypothesis

\begin{tabular}{|c|c|c|c|c|c|c|}
\hline $\begin{array}{l}\text { The moral of } \\
\text { the test mode } \\
\text { IP }\end{array}$ & $\begin{array}{l}\text { Model Test } \\
\text { Statistics F }\end{array}$ & $\begin{array}{l}\text { Coefficient of } \\
\text { interpretation } \\
\text { R2 }\end{array}$ & $\begin{array}{l}\text { The moral } \\
\text { of the } \\
\text { parameter } \\
\text { Sig. }\end{array}$ & $\begin{array}{l}\text { Parameter } \\
\text { Test } \\
\text { Statistics }\end{array}$ & $\begin{array}{l}\text { Regression } \\
\text { parameter } \\
\beta\end{array}$ & Regression paths (hypotheses( \\
\hline \multirow{5}{*}{.000} & \multirow{5}{*}{79.067} & \multirow{5}{*}{.66} & .000 & 8.378 & .423 & $\begin{array}{l}\text { The mental image of the company } \rightarrow \\
\text { economic dimension }\end{array}$ \\
\hline & & & .002 & 3.182 & .154 & Brand image $\rightarrow$ Economic dimension \\
\hline & & & .000 & 5.978 & .323 & $\begin{array}{l}\text { Product / Service Picture } \rightarrow \text { Economic } \\
\text { Dimension }\end{array}$ \\
\hline & & & .018 & 1.340 & .071 & $\begin{array}{l}\text { Image quality of product / service } \rightarrow \\
\text { Economic dimension }\end{array}$ \\
\hline & & & .312 & 1.013 & .055 & $\begin{array}{llll}\begin{array}{l}\text { Institutional identity } \\
\text { dimension }\end{array} & \rightarrow & \text { Economic } \\
\end{array}$ \\
\hline
\end{tabular}

Given Figure (1) of the graphical representation of the relationship between the dimensions of the company image and the economic dimension and at the level of this hypothesis among the sub-hypotheses of the first main hypothesis, it is clear to us the regression paths coefficients of beta values shown above the unidirectional arrows drop down from the company's five dimensions to the economic dimension of dimensions Social Responsibility

Figure 1 The regression paths between the dimensions of the corporate image and the economic dimension

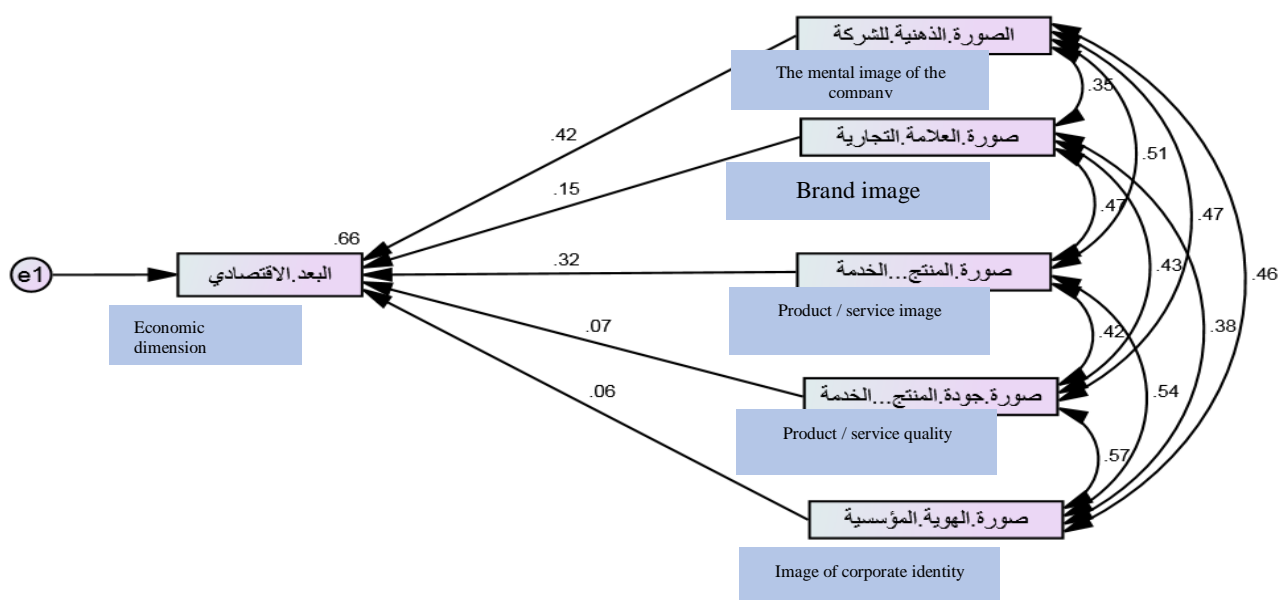


The second sub-hypothesis: the results of the test of thesecond sub-hypothesis showed that the continuity of the influence of the dimensions of the mental image of the company $154, \mathrm{P}=0.012(\beta=)$ and the brand image (34134, $P=0.015=\beta$ ) and after the image of the quality of the product / service with the strongest effect in the light. The value of the beta coefficient $(.324, \mathrm{P}=0.000$ $=\beta)$ as well as the significant dimension of the corporate identity image $(.222, P=0.001=\beta)$ is among the dimensions of the corporate image variable in the second legal dimension of social responsibility as an intermediate variable, as did not This hypothesis demonstrates the moral effect of the product / service quality image dimension $(0=0.05, \mathrm{P}>0.07)$ in this dimension of social responsibility, as well as on interpretive power. The overall model of the model in the light of the coefficient of determination was $(\mathrm{R} 2=$ $.50)$, which was also statistically significant $(\mathrm{P}=0.000)$, describing the contribution of the four dimensions mentioned $(50 \%)$ in the variation of the legal dimension, and the remaining proportion of the variance $(50 \%)$, Certainly due to other factors not included in the current research model.

The third sub-hypothesis: The test results of this hypothesis and shown in Table (28) have the effect of four-dimensional effect of the company's image variable, which is both the dimension of the mental image of the company. $148, \mathrm{P}=<.05=\beta$ ) and the brand image. After the picture of the quality of the product / service with the strongest effect according to the value of the beta coefficient $(3335, P=0.000=\beta)$ and after the institutional image $(78178, \mathrm{P}=0.008$ في (in the moral dimension the third dimension of the variable of social responsibility As an intermediate variable, no significant effect was found in the test results of the product / service image dimension $(0=0.05, \mathrm{P}>0.035)$, while the interpretation force of the model in terms of the coefficient of determination $(\mathrm{R} 2=.49)$ was found. Also for significant statistical total $(\mathrm{P}=0.000)$ contribution to describe the four dimensions mentioned by $(49 \%)$, in contrast to the legal dimension, in the sense that the legal side of the sample companies search Aissag isolation from the company's image in the minds of customers.

Sub-hypothesis 4: The test results of this hypothesis showed the significance of the four-dimensional effect of both the mental image of the company $(24=140, \mathrm{P}=$
$0.024)$ and after the brand image $(,=P=0.002)$. (157, $\mathrm{P}$ $=0.002=\beta$ ) After the picture of the quality of the product / service with the strongest effect according to the value of the beta coefficient $(.286, \mathrm{P}=0.002=\beta)$ is among the dimensions of the independent variable represented by the company image in the human dimension the fourth dimension of the variable of social responsibility As the test results did not prove a significant effect of the dimension of the corporate identity image ( $94=0.05, \mathrm{P}>0.094)$ in the economic dimension, while the strength of the coefficient of $(\mathrm{R} 2=$ .48) which was also statistically significant $(P=0.000)$, which reflects the variation (48\%) that is explained by the company's image by its dimensions, the mental image of the company, the brand image, the image of the product / service, the image The quality of the product / service in particular, from the variation of the human dimension under study and clear in the form of that relationship.

Sub-hypothesis 5: The test results and the apparent effect of this hypothesis showed the effect of four dimensions also for the company image variable, which are both the dimension of the brand image. $(166, \mathrm{P}=$ $0.007)=\beta)$ and after the product image service. $(242, P$ $=<.05$ بع 0 (and also after the product $/$ service quality image $(, 183, P=0.007)$ and the institutional image with the strongest impact $(28288, P=0.000=\beta)$ in the social dimension the fifth dimension of the intermediate variable social responsibility, and is not proven In the test results there was a significant effect of the dimension of the mental image of the company (.011, $\mathrm{P}>0.05=\beta$ ), while the value of the coefficient of interpretation of the model $(\mathrm{R} 2=.45)$, which also recorded a complete statistical significance $(\mathrm{P}=0.000$ Describes the contribution of the four dimensions mentioned $(45 \%)$ in the variation of the social dimension, in the sense that the social aspect of the research sample companies can not be built in isolation from the image of the company in the minds of society, or the remaining value of the coefficient of interpretation $(55 \%)$ subject to other phenomena were not Current search interests.

The sixth sub-hypothesis: the results of the test of this hypothesis showed the significance of the four dimensions of the company's image variable, which is both the dimension of the mental image of the company with the strongest effect and according to the value of 
the beta coefficient $.246, \mathrm{P}=.000(==)$ and the brand image. $\mathrm{P}=0.003)=\beta$ ) After the product $/$ service quality image $(,=126, \mathrm{P}=0.007)$ and after the institutional image $(,=169, \mathrm{P}=0.020)$ in the environmental dimension, the sixth dimension of the variable of social responsibility variable is the median variable, and is not The results of the test proved to have a significant effect on the dimension of the product / service image $(,=0.05,6.106)$, while the strength of the explanation coefficient $(\mathrm{R} 2=.40)$ was statistically significant $(P=0.000)$ describing the value of Tath. $T$ the four dimensions mentioned (40\%), in contrast to the environmental dimension, but for the remaining of the coefficient of determination $(60 \%)$ Other factors interpreted not covered by the current research within the model tested.

Sub-hypothesis 7: According to the results of this hypothesis, the significance of the dimensions of the mental image of the company is significant $(, 230, \mathrm{P}=$ $.000)$ and the brand image. In the cultural dimension, the seventh dimension of the median variable is social responsibility, and the results of the test have not been shown to have a significant effect on the dimension of the beta coefficient $(.235, P=0.000=\beta)$ and after the institutional image $(.205, \mathrm{P}=0.002=\beta)$. The product / service image $(,=0.05,100100)$, while the explanatory power according to the coefficient of determination (R2 $=.52)$ was statistically significant $(P=0.000)$ describing the value of the contribution of the four dimensions. Mention of $(52 \%)$ in the variation of the cultural dimension, while the remaining factor of the determination (48\%) was explained by other factors were not of the interests of the current research.

Test the second main hypothesis of the research: This hypothesis of the research focused on testing the relationship between the dimensions of the variable image of the company as an independent variable and the dimensions of the value of the customer as an approved variable, which represents the second step in testing the intermediate role of social responsibility in the relationship between the image of the company and the value of the customer, according to what is provided for these The hypothesis is one of the hypotheses of the current research, where four sub-hypotheses emerge from the results and presented in detail and respectively: The first sub-hypothesis: The test of this hypothesis, that four dimensions of the image of the company was in its effect relationship to the dimension of the value of the product significant and towards the directional, which is both the dimension of the mental image of the company and by beta coefficient had the strongest effect. $(283, P=0.000)=\beta)$ The image of the product / service, which was strongly influenced by and approached it, $p=<.01$ (01 013), and then the image of the product / service quality. $\mathrm{P}=<.01)=\beta$ ), with an explanatory power to this hypothetical hypothesis according to the coefficient of determination $(\mathrm{R} 2=.44$, $\mathrm{P}=0.000$ ), which explains the variance of the product value of the companies researched by this amount, either the values of Coefficient of determination not interpreted variables and other factors that are not included in the variables of this research.

The second sub-hypothesis: the results of the test of the fourth sub-hypothesis, show the significance of both the dimension of the mental image of the company. $(132, P=0.006)=\beta)$, the image of the product / service with a strong impact is the highest among the other dimensions and according to beta coefficient $251, \mathrm{P}=$ 0.000, (after the product / service quality image. $\mathrm{P}=<.082, \beta)$, and after the corporate identity image. $(191, P=<.05)=\beta)$ In the third dimension of the customer value variable of the personal value dimension While the results have not yet shown significant image of the trademark $.097, P=>.05=\beta$ ), the explanatory power of this hypothesis was quite significant according to the coefficient of determination $(\mathrm{R} 2=.34, \mathrm{P}=0.000)$ which explained the variation of value The The value of the non-explanation coefficient $(66 \%)$ was explained by other variables and factors not included in the variables of this research.

The third sub-hypothesis: The results of the test of the fourth sub-hypothesis had a significant threedimensional effect, both the dimension of the brand image with the strongest effect according to the value of the beta coefficient $(, 301, P=0.000=\beta)$ and after the image of the product / service which is followed by the force of impact $(.223, P=0.002=\beta)$ and then after the corporate identity image $(P=0.006 \beta)$. Among the dimensions of a company image as an independent variable in the service value dimension is the fourth dimension of the customer value variable as an approved variable, and the test results have not shown an effect. Significantly the dimension of the mental image of the company $(52=0.05, \mathrm{P}>0.05)$. $(\mathrm{R} 2=.40)$, which was completely statistically significant $(\mathrm{P}=$ 0.000), which reflects the variation (40\%) explained by 
the company's image across its three dimensions, the image of the brand, the image of the product / service, the image of the corporate identity in particular, from the variation After the value of the service studied in the context of achieving the objectives of the companies sample research aimed at improving the image of the company in front of its customers by achieving a higher value for the service provided, while the rest of the proportion of the coefficient of variance (60\%), certainly subject to other factors and variables of influence that were not among the concerns this search

Test the third main hypothesis of the research: This hypothesis and its four sub-hypotheses expressed to test the relationship between the intermediate variable, social responsibility, and the dependent variable, the value of the customer, including the independent variable, the company image, formulated as a control variable in the model of this test and according to the structural equation model ( The following is a detailed presentation of the test results of this hypothesis through its four sub-hypotheses described earlier in the first chapter of this research.

The first sub-hypothesis: The results of the test of this hypothesis that the moral effect of the dimensions of the social responsibility variable in the value of the customer, was limited to four dimensions of the legal dimension .076, $\mathrm{P}=0.031(\beta)$ and moral dimension .68, $P=0.038(=\beta)$ The cultural dimension with the strongest influence, according to the value of the beta regression coefficient, $\mathrm{p}=0.021$, environmental dimension. 159, $\mathrm{P}=0.001(\beta=0.001)$. Statistical effect of economic dimensions $(.00 .0, \mathrm{P}>0.05=\beta)$, human dimension $(01012, \mathrm{P}>0.05=\beta)$ and social dimension $(0065, \mathrm{P}>0.05=\beta)$. This model test, reached $(\mathrm{R} 2=$ .51 , which proved to Manoath in this complete statistical test $(\mathrm{P}=0.000)$

The second sub-hypothesis: the results of this hypothesis test that the moral effect of the dimensions of the social responsibility variable in the dimension of the mental image value, was limited to three dimensions of the moral dimension .098, $\mathrm{P}=0.025(\beta)$ and the human dimension. In the second dimension of the adopted variable, represented by the value of the mental image, while the results of the test did not record statistically significant in the effect of the economic dimension (-, p. $027, \mathrm{P}=0.044$,.(the legal dimension $(00.04, \mathrm{P}>0.05=$ $\beta)$, the environmental dimension $(.06=0.06, \mathrm{P}>0.05=$ ‘), the cultural dimension $(000.02, P>0.05=\beta)$, and the value of the coefficient of coefficient. D $(\mathrm{R} 2=.52)$, which proved its statistically significant significance in this test $(\mathrm{P}=0.000)$ explained the variance of its ratio $(52 \%)$ in the dimension of the mental image value, while the rest of it (48\%) is explained by other factors not taken into account In this research, I left the room for researchers to go into.

The third sub-hypothesis: that the moral effect of the dimensions of the social responsibility variable in the dimension of personality value was only three dimensions of the most powerful legal dimension and according to beta lab. (333, $\mathrm{P}=0.000$ (and the human dimension. The social dimension $(\mathrm{P}=0.046)=58$ (نتائر) in the third dimension of the adopted variable of personal value, while the results of the test did not record a statistically significant in the impact of the economic dimension and the moral dimension, the environmental dimension, and the cultural dimension $\mathrm{P}>$ 0.05). The results of the explanation coefficient were significantly statistically significant $(\mathrm{R} 2=.40, \mathrm{P}=$ 0.000). (40\%) after the personal value.

The fourth sub-hypothesis: The results of the test of the fourth sub-hypothesis, that the moral effect was limited to four dimensions and were both the moral dimension. $103, P=0.020(\beta=)$ and the human dimension. In the fourth dimension of the adopted variable of service value, the results of the test did not record a statistically significant effect on the economic dimension (-124, P = 0.008) and the cultural dimension , (0.05 = القانوني (the legal dimension $(01.016, \mathrm{P}>0.05=\beta)$ and the social dimension $(0096, \mathrm{P}>0.05=\beta$ ), but the explanatory power of the test model was $(\mathrm{R} 2=.46)$ which was significant Total Statistical a Also $(\mathrm{P}=0.000)$ in this test.

Test the fourth main hypothesis: The dimensions of social responsibility mediates the relationship between the dimensions of the company image variable and the dimensions of the customer value variable statistically significant. Secondary:

The first sub-hypothesis: the results of this test for the indirect effect showed the significance of the influence of the dimensions of the mental image of the company. $(423, P=0.000)=\beta)$, the brand image $.378, P=0.000)$ $=\beta)$ and the image of the product / service. $P=0.000)=$ $\beta$ ) and the product / service image $.071, P=0.000)=\beta$ ) in the economic dimension thereafter has an intermediate dimension in this hypothesis, as for the explanatory power of the adult paths and according to 
the value of the coefficient of determination $(\mathrm{R} 2=.66)$, This value explains the variation of the economic dimension in this ratio, which in turn was statistically significant $(\mathrm{P}=0.000)$. For a product, it was also significant $.058, \mathrm{P}=0.048(=)$, as well as direct effect results were also significant to diminish the mental image of the company with the strongest impact. (26, P $=0.000)=\beta$ ) and after the product / service image. , $\mathrm{P}=$ $0.001)=\beta$ ) and after the product quality / service image $.13, \mathrm{P}=0.050)=\beta$ ) and the image of the corporate identity. The contribution to these effects was reached according to the coefficient of determination $(\mathrm{R} 2=.44)$ with statistical significance $(\mathrm{P}=0.000$. (

The second sub-hypothesis: As for the indirect effect path, the results of the correlation between the dimensions of the company image and the economic dimension are fixed as explained in the first subhypothesis of the fourth main hypothesis. Dimensions of the customer value variable, were not significant .030, $\mathrm{P}$ $=0$. The effect of direct effect was significant for the dimensions of the product / service with the strongest effect. $(355, \mathrm{P}=0.000)=\beta)$ After the product / service quality image. $(315, \mathrm{P}=0.000)=\beta$ ) Institutional. $188, \mathrm{P}$ $=0.005 \quad($ دون $=($ Without the dimension of the mental image of the company and the brand image in the dimension of the mental image value, while the value of the coefficient of determination was $(\mathrm{R} 2=.49)$ with a statistically significant significance $(\mathrm{P}=0.000)$.

\section{CONCLUSIONS}

Interest in companies to maintain the image of customers in good form by providing offers at the best prices, which allows them to attract the largest number of users for its services provided, and the interest of companies to improve the mental image of them by providing the best prices and offers through the promotion of services and maintain survival In the mind of the customer and strive to provide the best always to prevent the loss of its brand in the mind of its customers through clarity, comprehensiveness and objectivity of the relevance of its products with the wishes of customers and keep abreast of changes through the study of the social reality of society, by owning Companies have a clear understanding to keep up with environmental and technological changes to provide a product that is consistent with the requirements and taste of the customer in order to maintain their competitive position, through solid knowledge bases in their fields, the management of research companies seek to provide high-quality products and services through continuous evaluation of the quality of their products and increase efficiency through the process of improvement Companies have been keen to harmonize their programs and objectives and in accordance with the goals of the customer and work to clarify its character through identity to dealers with customers, partners and employees and provide social benefits for them, and commitment to evil $\mathrm{S}$ implementation of instructions issued by the Ministry of Communications to help them legitimately possess market and legal share.

\section{SOURCES}

1.Abd-El-Salam ,Eman Mohamed, Shawky, Ayman Yehia\& El-Nahas.

2.Agarwal, Gautam, (2013) "The Impact of Corporate Social Responsibility on Consumer Behaviour" ,Masterthesis, Graduate School University of Milan Alnaser, FerasMI , Ghani, MazuriAbd , Rahi , Samar, Mansour, Majeed, \& Abed, Hussein . ( 2017 ) "Determinants of Customer Loyalty: The Role of Service Quality, Customer Satisfaction and Bank Image of Islamic Banks in Palestine” , International Journal of Economics \& Management Sciences, Vol : 6, Issue: 5.

3.Asamoah, Emmanuel Selase,.( 2012) "The effect of Corporate Social Responsibility on the competitiveness of firms in the Mobile Telecommunication industry in Ghana" , Accra, Department of Business Administration, Vol : 53 , No : 16.

4.Aslam, Wajeeha, Arif, Kashif\&Khursheed, Marium, ( 2018 ) "The Role of customer trust, service quality and value dimensions in determining satisfaction and loyalty: An Empirical study of mobile telecommunication industry in Pakistan', Market Trziste, Vol : 30 Issue : 31.

5.Carroll, A. B., (1979). " A Three-Dimensional Conceptual Model of Corporate Social Performance”, Academy of Management Review.

6.Drummond , Graeme \& Ensor , John . (2001) , “ Strategic Marketing Planning and Control “ , 
Chartered Institute of Marketing , 2 nd, British Library.

7.Kotler, Philip , Armstrong, Gary, Harris, Lloyd C. \& Piercy , Nigel. ( 2012 ) , "Principles of Marketing”, $6^{\text {th }}$, Pearson Education Limited,

8.Kumar, V. \&Reinartz, W.. (2010) “ The Mismanagement of customer loyalty” , Harvard Business Review, Vol : 86.

9.Maruf, Ayanda Adebayo. ( 2013 ) "Corporate Social Responsibity and Corporate Image", Transnational Journal of Science and Technology, Vol : 3, No : 8 .

10.Tawfik . (2013) " The impact of corporate image and reputation on service quality, customer satisfaction and customer loyalty: testing the mediating role. Case analysis in an international service company", The Business \& Management Review, Vol.3 Number-2 .

11.Yamamoto, GoncaTelli( 2002 ) “Understanding Customer Value Concept : Key to Success" Developments in Marketing Science, Vol. 20,. 